\title{
Development of a meandering channel caused by the planform shape of the river bank
}

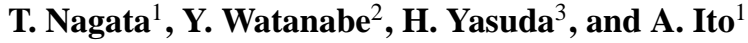 \\ ${ }^{1}$ Civil Engineering Research Institute for Cold Region, Public Works Research Institute, Japan \\ ${ }^{2}$ Department of Civil and Environmental Engineering, Kitami Institute of Technology, Japan \\ ${ }^{3}$ Research Center for Natural Hazard \& Disaster Recovery, Niigata University, Japan
}

Correspondence to: T. Nagata (03213@ ceri.go.jp)

Received: 15 October 2013 - Published in Earth Surf. Dynam. Discuss.: 20 November 2013

Revised: 7 March 2014 - Accepted: 24 March 2014 - Published: 30 April 2014

\begin{abstract}
Due to a typhoon and a stationary rain front, record amounts of rain fell in September 2011, and the largest class of discharge in recorded history was observed in the Otofuke River of eastern Hokkaido in Japan, and extensive bank erosion occurred in various parts of the river channel. Damages were especially serious in the middle reaches, where part of a dike was washed out. The results of a post-flood survey suggested that the direct cause of the dike breach was lateral advance of the bank erosion associated with the development of meandering channels. As the related development mechanism and predominant factors have not yet been clarified, this remains a priority from the viewpoint of disaster prevention. A past study on the development of meandering channels was reported by Shimizu et al. (1996). In this study, the meandering channel development process was reproduced using a slope failure model that linked bank erosion with bed changes. The study attempted to clarify the meandering development mechanism in the disaster and its predominant factors by using this model. The analysis properly reproduced the characteristics of the post-flood meandering waveforms. Therefore, it is suggested that the development of meandering during the flood attributed to the propagation of meandering downstream, which is triggered by the meandering flow from the meandering channel in the upstream, which also suggests that this propagated meandering then caused a gradual increase of meandering amplitude accompanied by bank erosion in the recession period of the flood.
\end{abstract}

\section{Introduction}

Due to a typhoon and a stationary rain front, a record amount of rain fell in September 2011. Discharge of the largest class was observed in the Otofuke River of the Tokachi River basin, and extensive bank erosion occurred in various parts of the river channel (Fig. 1). In the area near the left bank of KP18.2 at the middle reaches, where the erosion was the most severe, part of the river dike was almost entirely washed away (Fig. 2). Post-flood surveys revealed the direct cause of the dike breach to be the bank erosion that progressed during the development of meandering flow in the low-water channel. However, since the development of meandering flow on such a great scale was never observed for this river, the mechanism and dominant factors of this phenomenon are not fully understood. Clarifying the mechanism and dominant factors of this phenomenon is an urgent issue toward developing and implementing appropriate and effective preventive measures.

A distinguishing feature of this flood is that the extreme discharge continued for a long time, filling the low-flow channel almost to the crest $(40 \mathrm{~h}$ at the average maximum yearly discharge of $155 \mathrm{~m}^{3} \mathrm{~s}^{-1}$ ), which shows that channel migration during the flood was dominated by the action of the water flow running through the low-water channel and suggests that channel migration was associated with the mechanism of sandbar development. Additionally, the flow channel geometry left after the flood had the pattern of a single low watercourse that extensively meandered between the dikes due to the erosion of the low-water channel, which suggests that the channel migration was associated with the mechanism of meandering channel development. That is to 


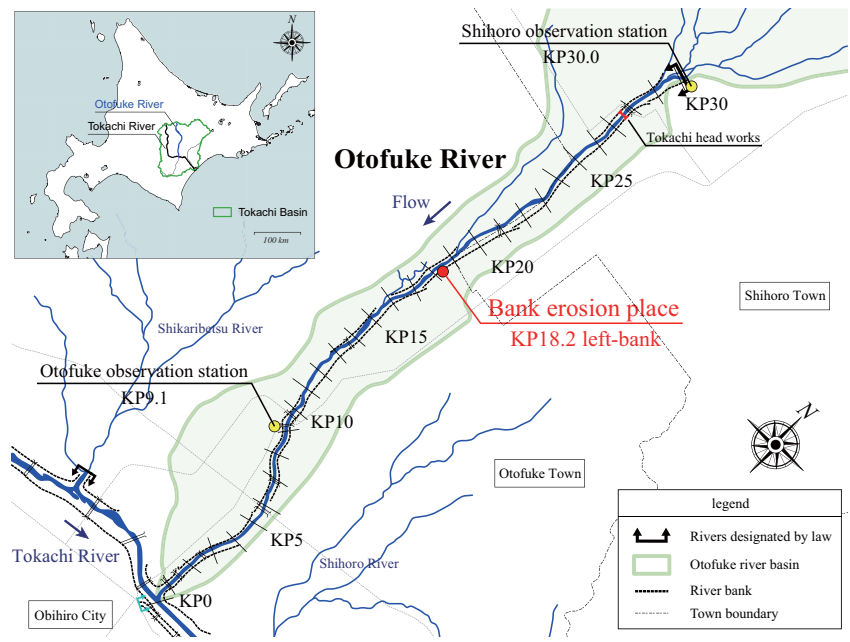

Figure 1. Bank disaster area (Otofuke River, Hokkaido, Japan).

say, there is a possibility that the development of meandering flows in the flood occurred under the interrelated influence between the mechanism of sandbar development and the mechanism of meandering channel development operating in the low-water channel.

Previous studies conducted by the authors (e.g., Nagata et al., 2013) addressed sandbar topography as a factor in the development of meandering flow. Experiments and analyses confirmed that the topography of alternating bars can be a factor in the development of meandering channels. However, the phenomenon that occurred in the area around the damaged bank of the Otofuke River was so dynamic that even the wave number of meandering channels decreased; therefore, it is difficult to fully explain some aspects of this phenomenon only by the development of gravel-bar-derived meandering flow.

The most dominant factor after sandbar topography is the planar configuration of the riverbank. As confirmed in a field survey, the riverbank of a low-water channel sometimes forms with an extremely developed sandbar; therefore, there is no substantial difference between them as topographyderived factors. A sandbar whose wave height has increased to the height of the low-water riverbank is assumed to behave like a low-water riverbank, in the sense that the sandbar redirects the flood flow that runs in the low-water channel.

In light of the above, this study addresses both the sandbar topography and the planar configuration of the low-water riverbank and conducts various examinations using numerical analysis toward identifying major factors in damage to this river dike.

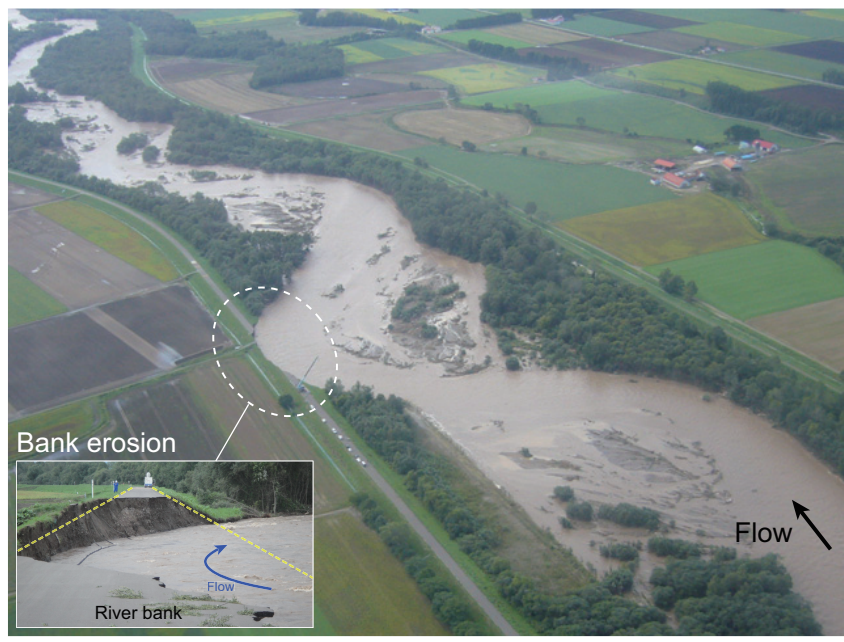

Figure 2. Situation at the time of bank disaster (7 Sep. 2011).

\section{River channel evolution process}

\subsection{Major external forces and the river channel formation process}

To estimate the factors that brought about the bank disaster, the river channel formation process was investigated in the section extending from KP17.0 to KP21.0, which includes the damaged location. The aerial photos in Fig. 3 indicate the typical changes that took place in the river channel during the roughly 30 year period from the late 1970 s to the post-flood time. The chronological table (on the left) shows river improvement work, which is an unnatural external force; major floods, which are a nature-derived external force; and an image of the meandering channel that developed as a result of those forces. In this section, large-scale river work was performed in the 1970s to straighten the low-water channel, and this period is marked as a starting point of the river channel formation that has been continuing up to the present. After that, the largest recorded flood took place, in 1981, and it triggered the further development of meandering channels.

Figure 4 shows the flow regime of the period when discharge decreased during the 1981 flood. The red line represents the riverbank of the low-water channel along the normal line of river channel, and the blue line represents the main streamline. At this point, three large meandering parts had already formed in the upstream section (KP18.4KP21.0), and as shown in Fig. 3, these flows (hereinafter: M-1, M-2 and M-3 from downstream to upstream) gradually increased the degree of meandering over the period of 30 years.

In addition, due to the state of the river channel in 2005, river work was again performed to straighten the low-water channel immediately downstream of KP18.6, where the turning point of meandering curvature had come close to the river dike. The upstream side of KP18.6 is surrounded by 

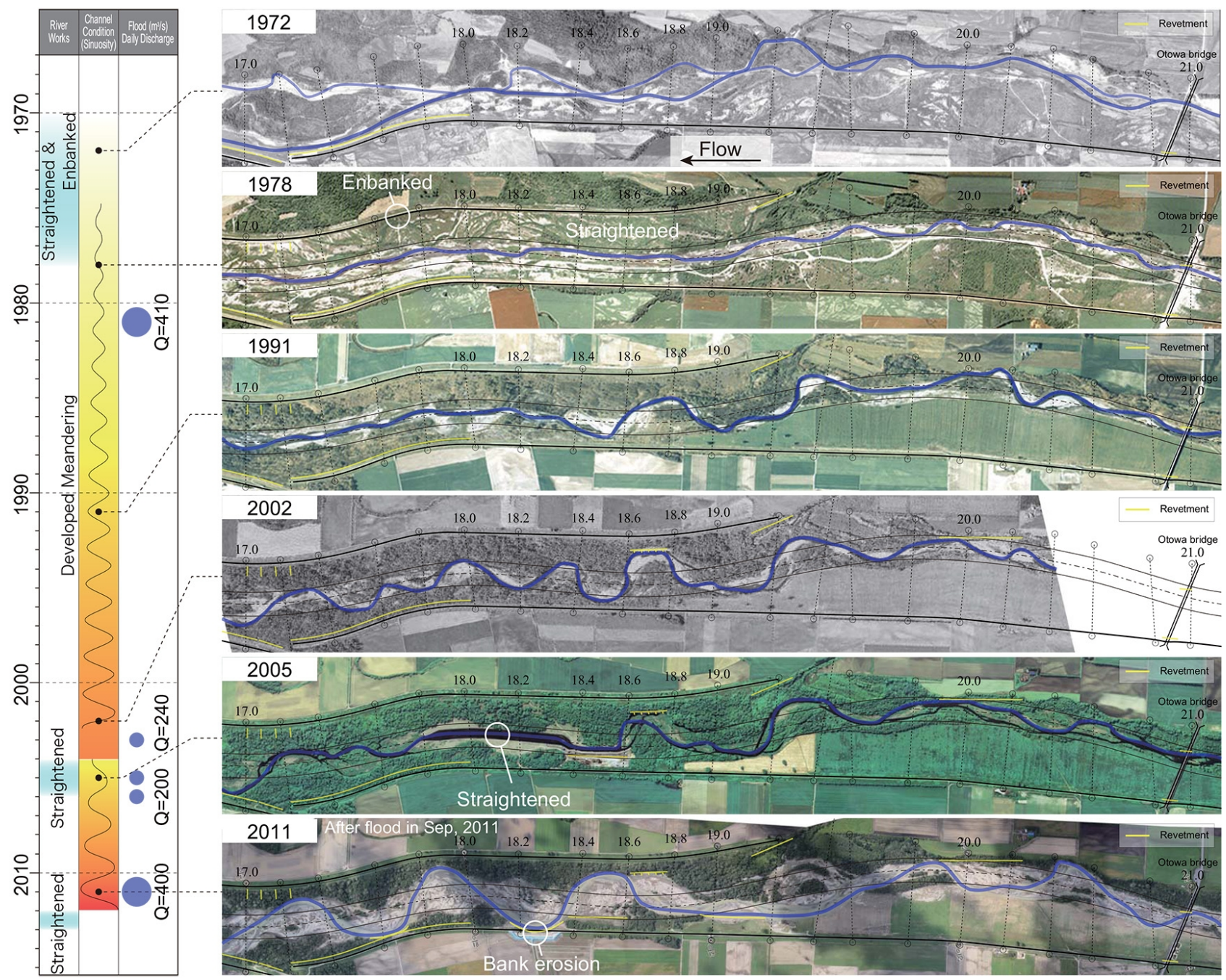

Figure 3. Migration history of the river channel (Otofuke River, KP17.0-KP21.0).

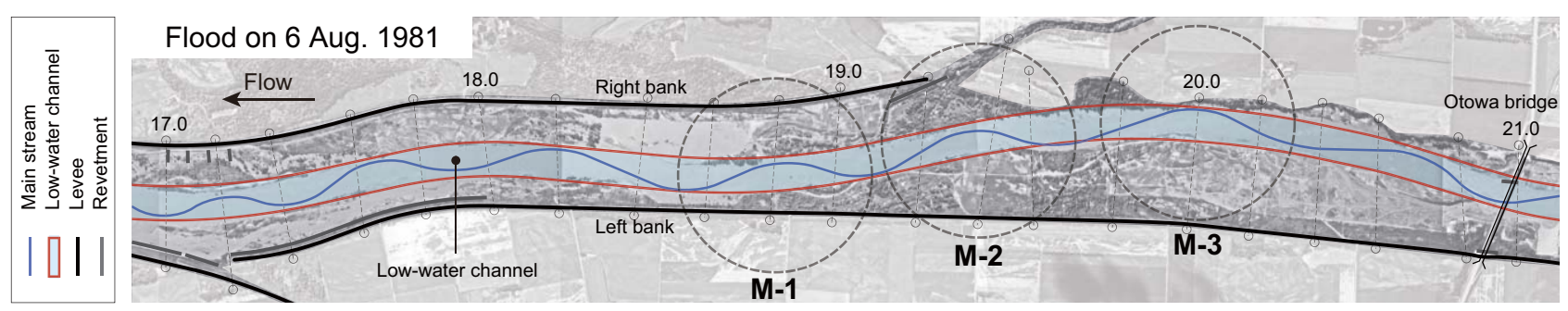

Figure 4. Main streamline and front bank line of the low-water channel during the 1981 flood (recession period).

a floodplain and terraces that have been serving as an embankment; thus, safety has been ensured. Therefore, largescale river improvement work had never been performed there. Hence, it is reasonable to assume that there was a major difference in the state of the river channel between the upstream side of the KP18.6 area and downstream side of the KP18.6 area. In light of this on-site situation, analysis was performed separately for the upstream section versus for the downstream section. KP18.4-KP21.0, which is on the upstream side, is referred to as Section-1; KP17.0-KP19.0, which is on the downstream side, is referred to as Section-2. In addition, there is an overlap between two sections, because the meandering part in M-1 plays a key role in this analysis, which will be discussed later. 


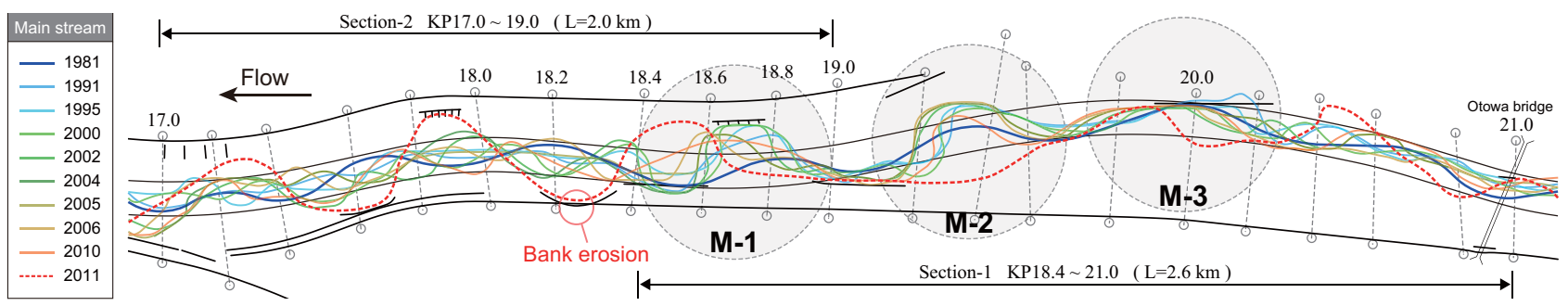

Figure 5. Changes in the configuration of meandering channels (1981-2011, KP17.0-KP21.0).

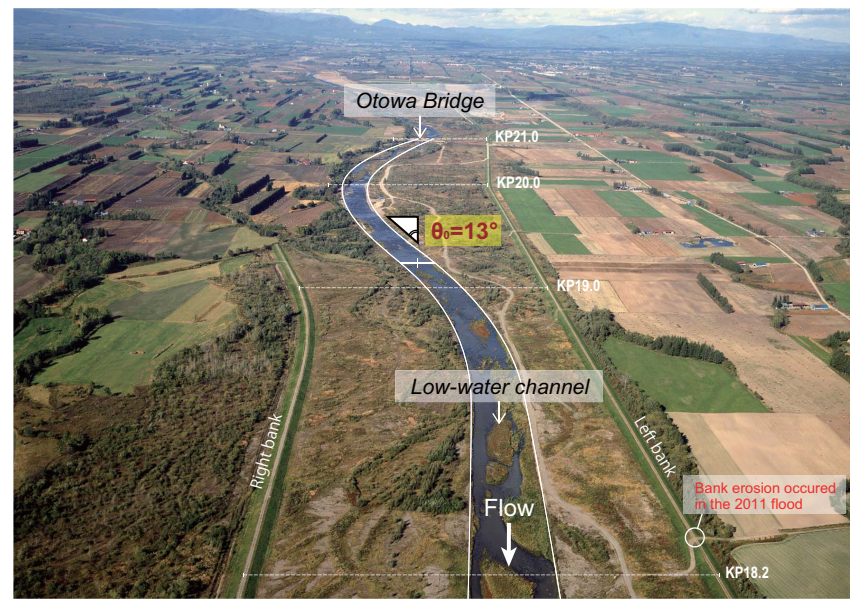

Figure 6. Planform shape of the low-water channel in 1978.

\subsection{Watercourse change}

Figure 5 diagrams the horizontal curve of the main streamline from the aerial photos taken in 10 different years over the past 30 years. The changes from 1981 to 2010 show that the watercourse shifted repeatedly and irregularly toward the left and right banks immediately downstream of KP18.6. In contrast, M-1, M-2 and M-3, which are on the upstream side of KP18.6, shifted their phase slightly downstreamward, while shifting their waveforms forward. Also, M-1, M-2 and M3 increased the degree of meandering in a single direction; however, the sandbar remained at an almost fixed position. Thus, the upstream side shows changes that are obviously different from those of the downstream side.

In general, in a straight river channel, alternating bars tend to move along the direction of flow; in a meandering channel, however, they have the property of remaining roughly stationary. Kinoshita found that sandbar movement and lack of movement are determined by the meandering wavelength, the channel width and the meandering angle of the channel, and that the meandering angle has a certain limiting gradient at which sandbars stop moving (e.g., Kinoshita et al., 1974). As clearly shown in Fig. 5, the normal line in the low-water channel forms a large curvature whose vertex is near KP20.0. That is to say, the above finding suggests the possibility that the planform shape of the riverbank of the low-water channel induced the development of point bars in M-1, M-2 and M-3.

\section{Relation between bend of the normal line in low- water channels and development of point bars}

Given the above background, an analysis was made of Section-1 (KP18.4-21.0) at first with the aim of evaluating the relation between the bend of the normal line in lowwater channels and the development of point bars in M-1, M-2 and M-3. In identifying dominant factors in phenomena that occur in the field, it is more appropriate to conduct model tests under simplified conditions than to analyze complex field data. Therefore, the authors had already conducted a movable-bed hydraulic model test under various conditions before conducting this study. The reproducibility of the sediment transport formula used in this study was tested on the basis of measurement values obtained in this model test.

In the model test, in order to maintain the similarity of the hydraulic and sediment transport phenomena between the site and the model, various experimental conditions in the model test were set such that the values of the dimensionless quantity $\left(\mathrm{Fr}, \tau_{*}\right)$, which have a dominant impact on both phenomena, would be consistent. This resulted in maintaining the similarity of width/depth ratio, which greatly affects the formation and configuration characteristics of alternating bars, at the same time. However, perfect similarity cannot be maintained between the actual river and the model (similarity of the Reynolds number of the particles is not fulfilled). Therefore, it is unclear how much applicability the sediment transport formula, whose reproducibility was confirmed in the model-scale experiment, will have in a full-scale experiment. In addition, it is difficult to measure sediment transport during a flood, which means that it is also difficult to perform comparative verification using measured values.

Given the above, it was determined to be appropriate to perform the analysis at a model scale that was confirmed to be able to reproduce hydraulic and sediment transport phenomena, and then to convert the obtained results to those at actual scale and discuss the phenomena that occurred at the actual place. Note that, hereinafter, in order to achieve consistency with previous studies (e.g., Nagata et al., 2013), the analysis was conducted at $1: 100$ scale; however, in order to 


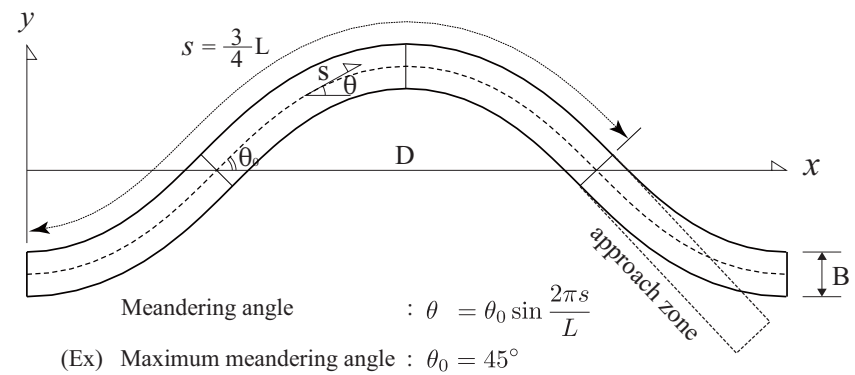

Figure 7. Definition of the sine-generated curve.

facilitate the comparison with the actual site, in this paper, the numerical values obtained in the calculation results are converted into actual measurement values.

\subsection{Calculation condition (Section-1)}

As the initial condition of the river channel in Section-1, the channel configuration after the river was channelized into a straighter channel with only low-amplitude curvature (Fig. 6: before the 1981 flood) and was simplified as follows. In the planform shape of the low-water channel, the normal line in the low-water channel was approximated by the sinegenerated-curve shown in Fig. 7, and the low-water channel represented by the red line in Fig. 5 was designed to be a meandering channel with a meandering angle $\theta_{0}$ of $13^{\circ}$ and river width of $100 \mathrm{~m}$. On the basis of previous survey data, the cross-section profile of the low-water channel was designed to have a $2 \mathrm{~m}$-high bank with a slope gradient of $2: 1$, and the riverbed surface was designed to give particle-sized disturbance to the flat bed. The left and right sides of the low-water channel were provided with a $100 \mathrm{~m}$-wide floodplain that allows bank erosion, and the entire calculation area was a movable riverbed. A longitudinal slope of 0.00610 was used, which was the average value for Section-1.

Incidentally, since a bridge (Otowa Bridge) was built near KP21.0 at the actual site in Otofuke, this point was determined to be the upstream end of the analysis section, and a straight river channel that did not include curvature was set on the farther upstream side as an approach zone and was connected to the analysis section.

Figure 8 compares discharge hydrographs of previous major floods. The results of the analysis for Section-1 make it possible to understand the characteristics of bed morphology formed by the 1981 flood, in addition to how the riverbed responded to the steady flow. The figure shows that the discharge of the 1981 flood had a scale comparable to the design-flood discharge. In addition, the 2011 flood fell below the 1981 flood in terms of discharge during peak discharge; however, the 2011 flood exceeded the 1981 flood in terms of the duration of the average annual maximum discharge.

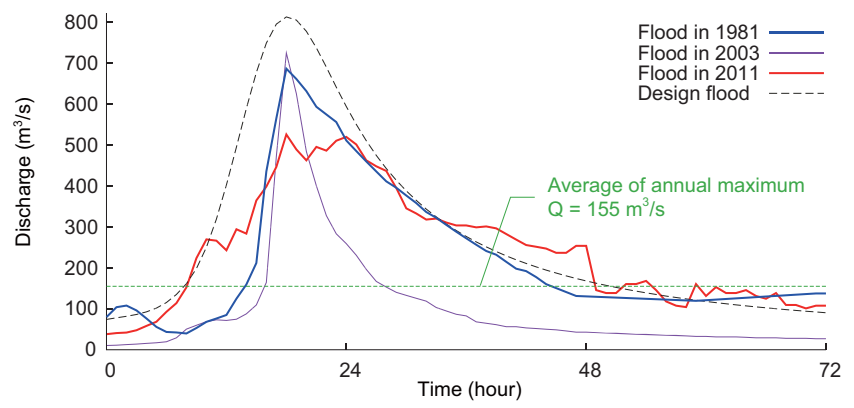

Figure 8. Discharge hydrographs of the major floods.

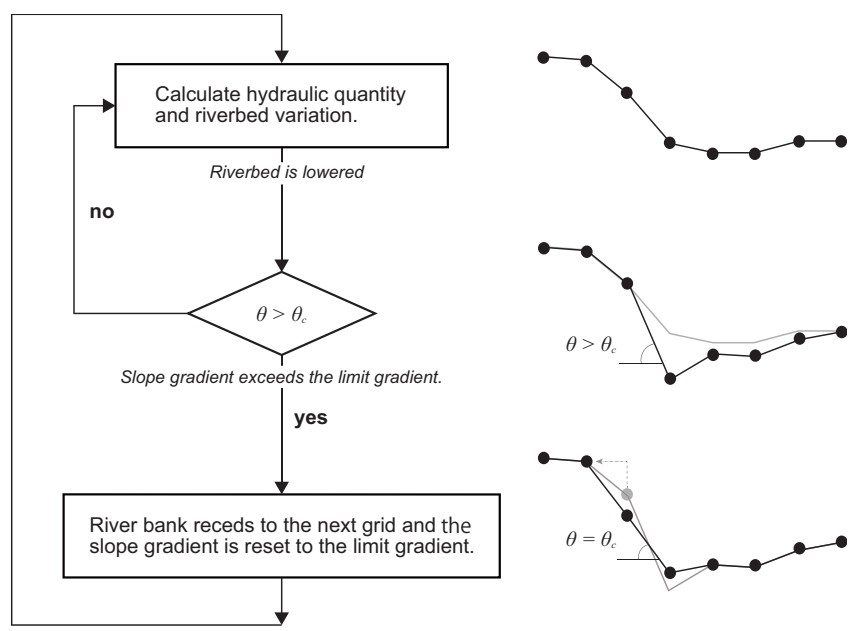

Figure 9. Slope failure model (refer to Nays2D solver manual).

\subsection{Calculation model}

The analysis performed in this study used the iRIC river analysis software package and its solver Nays2D v4.0 developed by Shimizu (e.g., Shimizu, 2003). Governing equations used in the model are a two-dimensional plane, shallowflow equation for the unsteady flow and a continuous flow formula; and the amount of riverbed evolution is calculated by a sediment transport formula and the continuous formula of sediment transport. Details are omitted here. Please refer to the website of iRIC (http://i-ric.org/en/) for more information. In addition, for calculating the sediment transport, Eq. (1) was used, which was developed on the basis of the Ashida-Michiue formula by adjusting the coefficients of the formula in light of previous experimental results.

As Wong and Parker showed that the coefficient of MeyerPeter and Müller equation is excessive in the past study (e.g., Wong and Parker, 2006), and Lajeunesse and others organized the coefficient of sediment transport equation that was used in the past (e.g., Lajeunesse et al., 2010), various values are proposed for the coefficient of sediment transport equation. Equation (1) shows a near value by the Meyer-Peter and Müller equation that Wong and Parker showed in comparison 
to an original Ashida-Michiue formula (coefficient: 17).

$q_{\mathrm{b}}=13 \tau_{*}^{1.5}\left(1-\frac{\tau_{* c}}{\tau_{*}}\right)\left(1-\sqrt{\frac{\tau_{* c}}{\tau_{*}}}\right) \sqrt{s g d^{3}}$

The details are as follows: $q_{\mathrm{b}}$, bedload transport rate per unit width $\left(\mathrm{m}^{2} \mathrm{~s}^{-1}\right) ; \tau_{*}$, dimensionless tractive force; $\tau_{* c}$, dimensionless critical bed shear stress (Iwagaki formula); $s$, specific gravity of sand grains; $g$, gravitational acceleration $\left(\mathrm{m}^{2} \mathrm{~s}^{-1}\right)$; and $d$, sand grain size $(\mathrm{m})$.

$n=\frac{d^{1 / 6}}{6.8 \sqrt{g}}$

The grain size of bed material was determined to be $d_{60}=$ $50 \mathrm{~mm}$ from the survey results of 2011, and the ManningStrickler formula shown in Eq. (2) was used to obtain the roughness coefficient. In setting a condition for sediment transport it was determined to use only bedload sediment, which was regarded as having the same grain size.

Furthermore, in the present study, a slope failure model was used to reproduce the bank erosion phenomenon (Fig. 9). This model is designed such that the low-water riverbank is simulated to collapse naturally when the slope gradient exceeds a certain limit; thus, the bank erosion phenomenon is reproduced indirectly by moving the riverbank backward to maintain the limiting gradient; at which time the sediment budget is balanced by backfilling the lower part of the riverbed with the collapsed sediment. Since the present model is not intended to physically solve for bank erosion phenomena, there still remains the challenge that the results of the analysis depend on the choice of computational grid; however, previous studies have proved that the development of meandering flow is able to be reproduced to a certain degree. In this analysis, the limiting gradient of the slope is set as $\theta_{c}=25^{\circ}$. Additionally, in all the simulations in this study, uniform flow depth was given as a boundary condition at the downstream edge of the analysis section and sediment budget at the upstream edge was assumed to maintain a state of equilibrium.

\subsection{Calculation results (Section-1)}

Riverbed elevations after 3 days of steady flow are compared in the plan view of the riverbed elevations in Fig. 10. The figure shows the elevation differences of the riverbeds as compared by using a constant bed slope of 0.00610 . Hereafter, elevation differences are compared in the same manner.

The results shown in the figure suggest that discharge of $300 \mathrm{~m}^{3} \mathrm{~s}^{-1}$ had a dominant influence on the development of the meandering flows. Moreover, what should be noted here is that the locations of the meandering channels (point bars) formed on the downstream side of the bend of the river channel and at intervals between them. Wavelengths slightly varied depending on the scale of discharge; however, the meandering channels that have wavelengths of approximately $600 \mathrm{~m}$, formed at almost regular intervals. These meandering channels are equivalent to M-1, M-2 and M-3 at the actual field site along the Otofuke River, and the locations and intervals of the meandering channels in the analysis are roughly in accordance with those at the site shown in Fig. 3 (meandering channel configurations: 1991-2005, KP18.5-KP20.3).

Next, riverbed elevations were compared after discharge with the same flow rate as that of the 1981 flood was introduced for 3 days (red line in Fig. 8), which is shown in the plan view of the riverbed elevations in Fig. 11. In the figure, the blue dotted line represents the configuration of the main stream in the recession period of the 1981 flood (blue line in Fig. 4), and the red line represents the configuration of the main stream during the low-water discharge in 1991. The analysis results show that three meandering parts (M-1, M-2 and M-3) that had wavelengths of approximately $600 \mathrm{~m}$ formed at regular intervals in the $1.8 \mathrm{~km}$-long section. Comparison between the configuration of the flow channels shown in calculation results and those in 1981 or 1991 shows that the locations and intervals of the meandering channels are roughly in accordance with those in 1981 or 1991.

The results above suggest the possibility that the meanders formed at an actual location where the point bars were necessarily brought about due to the curvature of the normal line in the low-water channel or the planform shape of the river bank.

\subsection{River channel formation process during 1981 flood}

Factors that led to the formation of the above-mentioned sandbars will be discussed on the basis of the transition process of bed morphology during the flood. Figure 12 shows the calculated river channel formation during the period when discharge was lower in the 1981 flood, and the displayed time of each result corresponds to each displayed time of from (1) to (6) in Fig.13. The transition process of bed morphology during the flood can be roughly described as follows: a sign of change started to appear on the surface of the riverbed after the peak discharge, and then multiple-row bars on the riverbeds changed into double-row bars over time. For the time period from (5) to (6), differences in bed morphology are found between the section immediately upstream of the bend and the section immediately downstream of the bend in the river channel. While double-row bars still remain in the upstream section, the trend toward the development of single-row bars is already clearly seen in the downstream section. This is probably because the downstreamward migration of the sandbar was limited at the bend in the river channel, which provided conditions better than a straight river channel for the development of sandbars, and the developed sandbars eventually completely stopped moving, which then promoted the development of single-row bars. However, it is unknown whether such a phenomenon was taking place in the actual river. But in calculation, it describes the spinup process in the numerical model as the flow transitions 


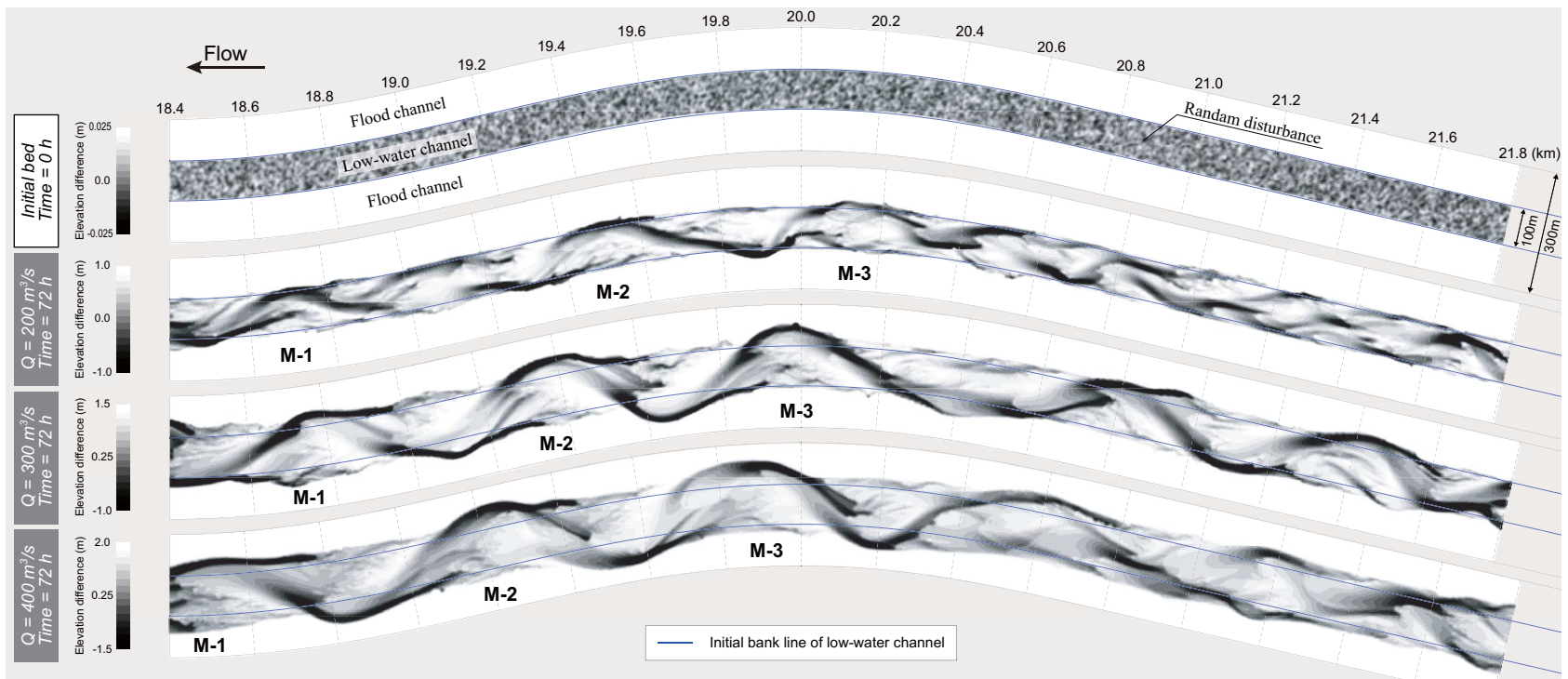

Figure 10. Analysis results of steady flow in Section-1 (riverbed elevation).

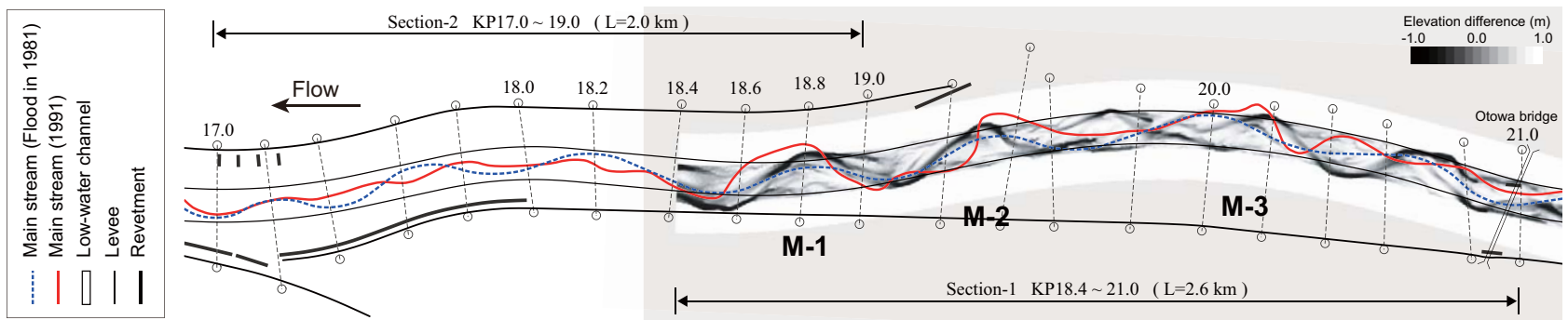

Figure 11. Analysis results of the 1981 flood in Section-1 (riverbed elevation).

from the plane bed through small-scale multiple-row bars to single-row alternate bars.

Further, it was observed in this analysis that sandbars in M-1, which formed immediately downstream of the bend, eventually triggered the development of sandbars in M-2 on the upstream side, and those sandbars then gradually increased the degree of meandering. That is, it is considered that, since point bars that form in the bend area of the river channel can even limit the migration of sandbars on the upstream side, the impact from those point bars will spread further upstream indirectly.

\subsection{Influence of meandering angle on the development of meandering channels}

As already mentioned, the on-site normal line in the lowwater channel has a planform shape with a meandering angle of $\theta_{0}=13^{\circ}$. Analysis results suggest the possibility that the planform shape of the low-water channel limits the migration of sandbars and induces the development of point bars near the river bend. From this, the next step is to evaluate how differences in the meandering angle of a curved river channel influence the development of a meandering channel and the limiting gradient that stops the migration of sandbars. For the calculation condition, that used in the previous analysis was adopted, and the development of meandering channels after the 3 day flood of 1981 was evaluated, with only the meandering angle being changed within the range of $\theta_{0}=0 \sim$ $26^{\circ}$.

Some examples of the calculation results are shown in Fig. 14. Additionally, as shown in Fig. 15, this calculation condition can allow the trend toward the development of single-row bars even in a straight channel (meandering angle $\theta_{0}=0^{\circ}$ ), because single-row bars can develop even in a straight channel around the peak discharge. Therefore, it is difficult to extract only the influence that the curvature of the river channel has on the development of single-row bars; however, it is possible to evaluate the influence of the difference in meandering angle on the development of meandering channels to some degree by comparing the development of meandering channels using the river channel configurations with the meandering angle of $\theta_{0}=0^{\circ}$ as a benchmark.

Figure 14 shows the general trend in which the riverbed configurations become double-row bars with decreases in 


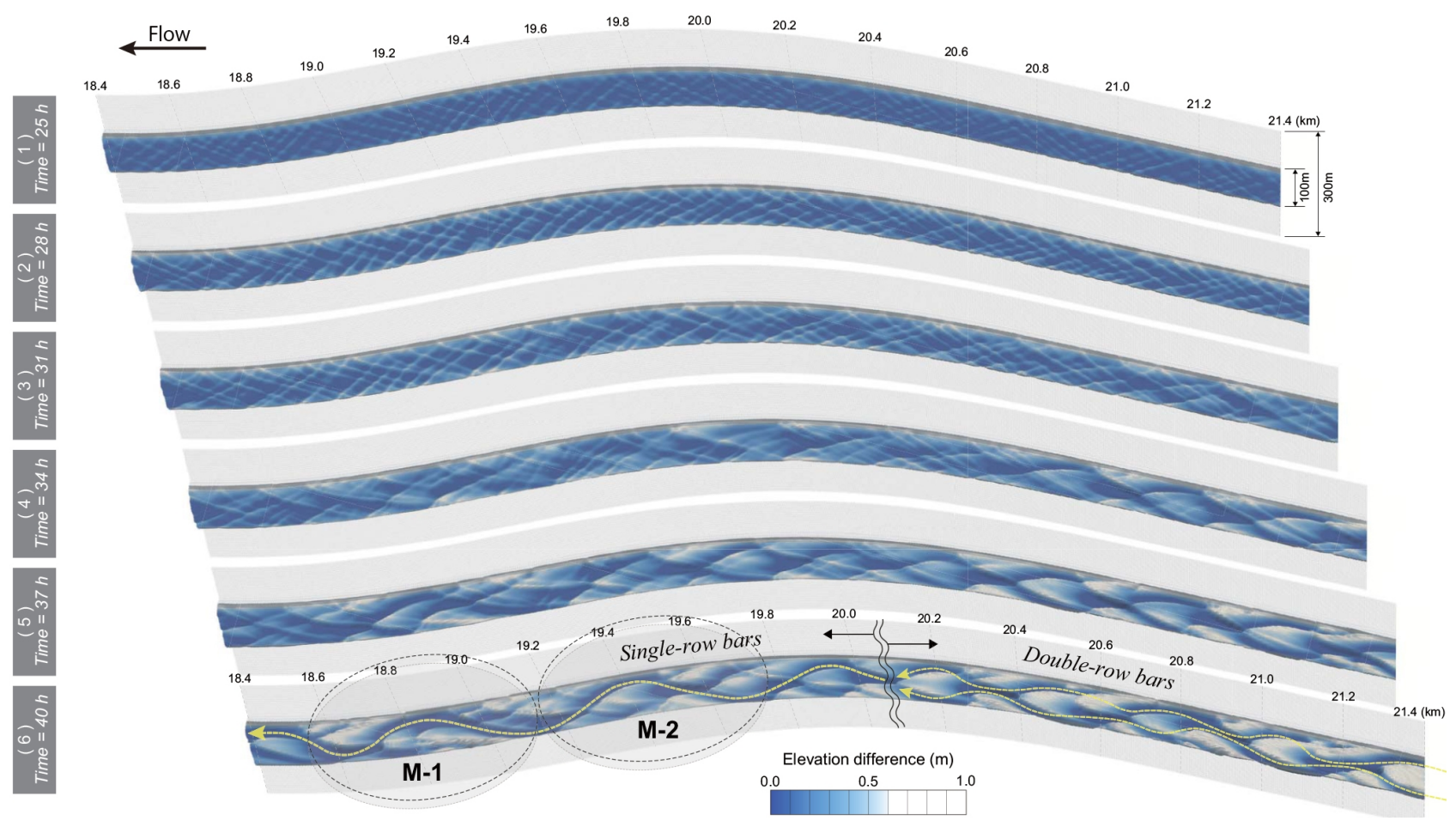

Figure 12. River channel formation process after peak discharge (1981 flood, KP18.4-KP21.4, Section-1).

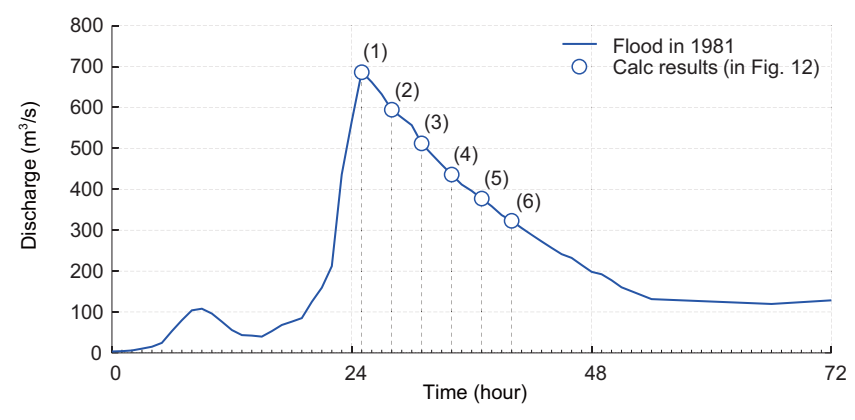

Figure 13. Display time of calculation results (1981 flood).

meandering angle, and in which the trend toward the development of single-row bars is observed to become clearer with increases in the meandering angle. In particular, in the meanders, M-1, M-2 and M-3, which are the colored parts in the figure, comparatively sharply defined point bars were formed when the meandering angle was around $\theta_{0}=10^{\circ}$ or more.

\section{Propagation of meandering waveforms resulting from the planform shape of the river bank}

As mentioned above, the analysis of Section-1 suggests that the meanders (M-1, M-2 and M-3) that formed in the section between KP18.4 and KP21.0 are point bars inevitably resulting from the curvature of the normal line in the low-water channel. Also, from the history of the river course migra- tion, it was found that large-scale river improvement work had never been performed in this section during the 30 year period and that these three sandbars had remained at roughly the same location since the 1981 flood, despite year after year of increases in the degree of meandering.

It is believed that a highly developed sandbar is functionally equivalent to the riverbank at the low-water channel and can strongly direct flood flow toward the right or the left river bank, and thus it promotes the development of the meandering channels. In other words, the development of sandbars in M-1 is considered to have had a significant impact on the bank disaster (near KP18.2) that occurred immediately downstream. Therefore, in the next step, data obtained from Section-2 (KP17.0-KP19.0), which includes the sandbars in $\mathrm{M}-1$ and the area around the damaged location, are analyzed.

\subsection{Development of point bars in $\mathrm{M}-1$}

First, in order to model the conditions of the river channels to be used in the analysis, the details of the development of the point bars in M-1 before the 2011 flood were confirmed. Figures 16 and 17 show the conditions of the river channel in Section-2 based on the laser profiler (LP) measurement data obtained in 2006. Figure 16 (left) is a bird's-eye view and Fig. 16 (right) is a transverse section of M-1, while Fig. 17 is a plan view of the riverbed elevation. In the transverse section of M-1, Bar-1, which formed on the left-bank side, developed to the point of completely filling up the low-water channel 


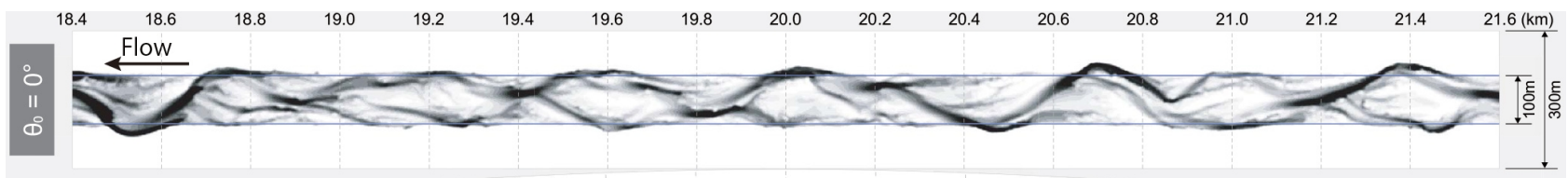

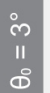
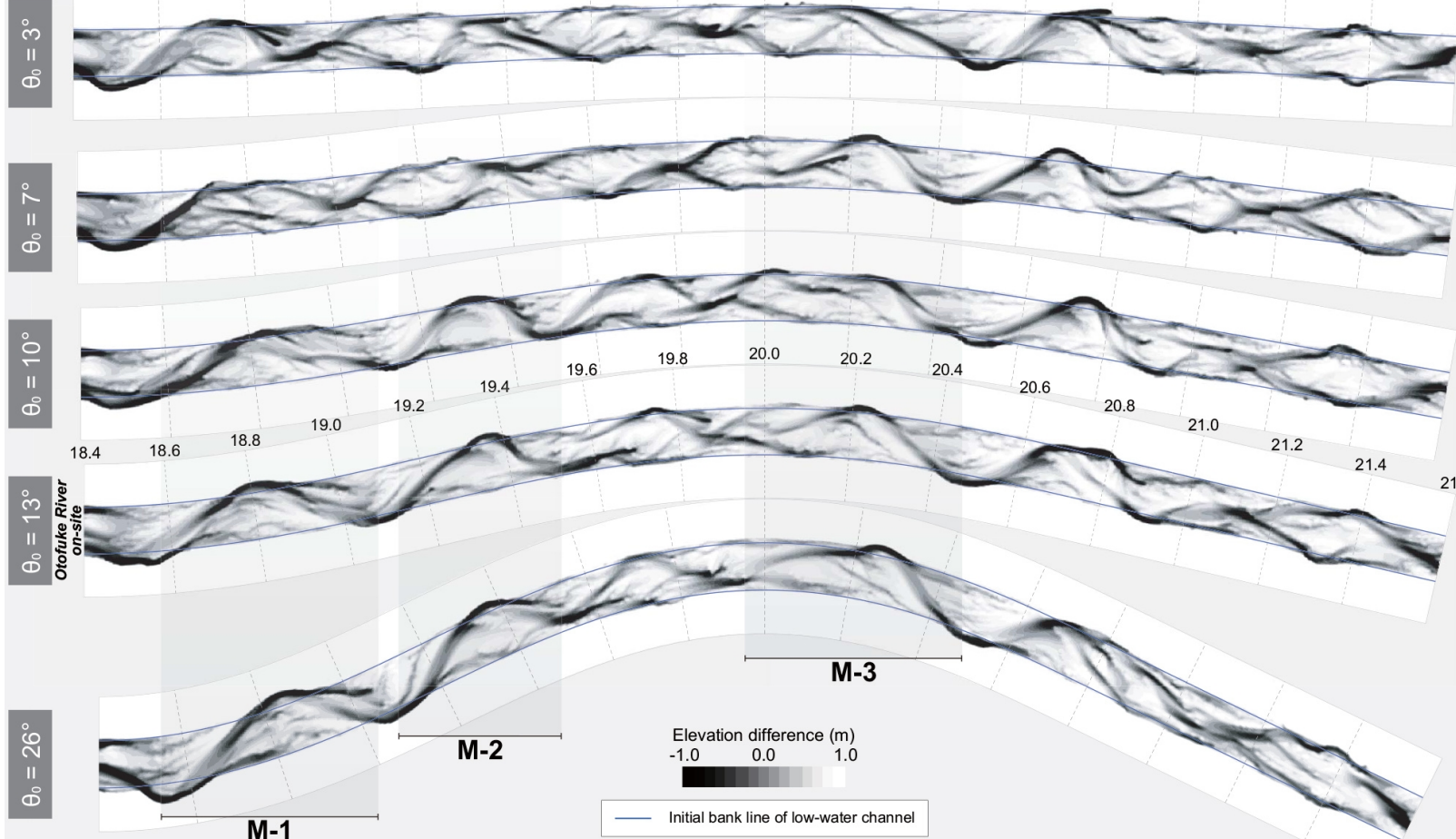

Figure 14. Development of meandering channels at various meandering angles (1981 flood, KP18.4-KP21.6).

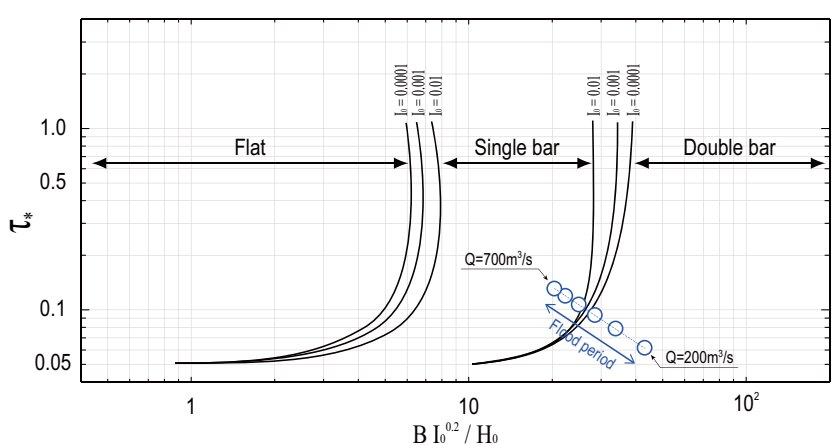

Figure 15. Mesoscale bed morphology classification (e.g., Kuroki and Kishi, 1983) during the 1981 flood.

that is indicated by the red dotted line for 1981, which shows that solid point bars, whose wave heights were as high as the crest of the riverbank in low-water channel, formed.

In this analysis, the terrain model was simplified as much as possible by extracting only major points of the on-site river channel configuration, for the purpose of identifying the dominant factors in the development of meandering flows.
Major points included the following: the low-water channel on the upstream side of the damaged location was curved sharply toward the right bank due to the developed point bar (M-1), and the downstream section still included a straight channel, since river improvement work was performed in 2005.

Thus, a planform-shaped riverbank that was designed to imitate the meandering path (M-1), as shown by the dotted line in Fig. 17, was formed on the upstream side of the analysis section, and a straight river channel with a $100 \mathrm{~m}$-wide low-water channel was connected to the section on the downstream side. More information on the planar configuration of the riverbank is shown in the uppermost part of Fig. 21.

\subsection{Calculation conditions (Section-2)}

In this analysis, the 2011 flood (3 days), shown in Fig. 18, was reproduced as an external force, with the purpose of identifying the dominant factors that triggered the development of meandering flows that caused the bank disaster, in addition to the developing process of the meandering flows being examined. The $2 \mathrm{~km}$-long section from KP17.0 to KP19.0 was determined as the section for analysis, and 

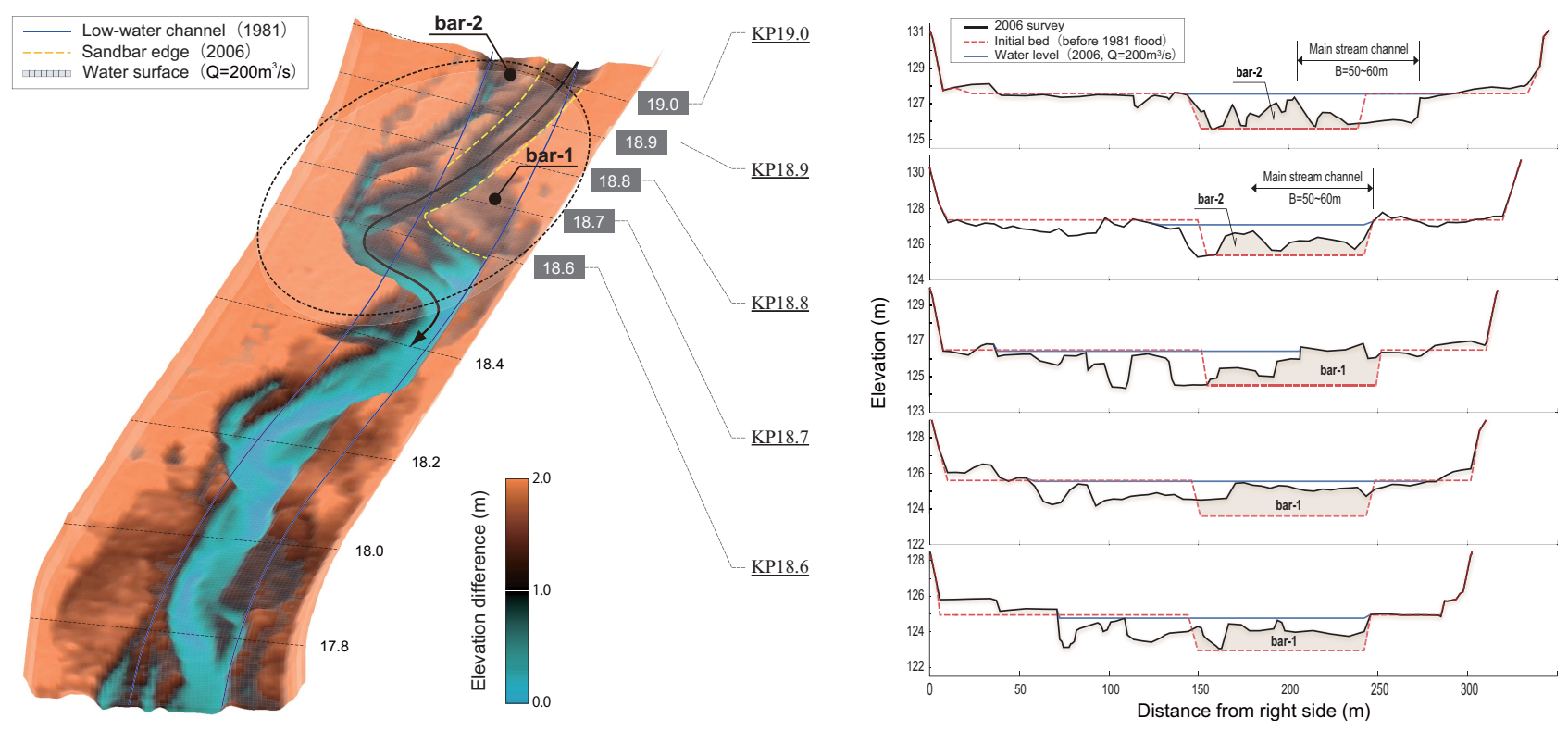

Figure 16. Development of sandbars before the 2011 flood (LP data: 2006.5, Section-2).

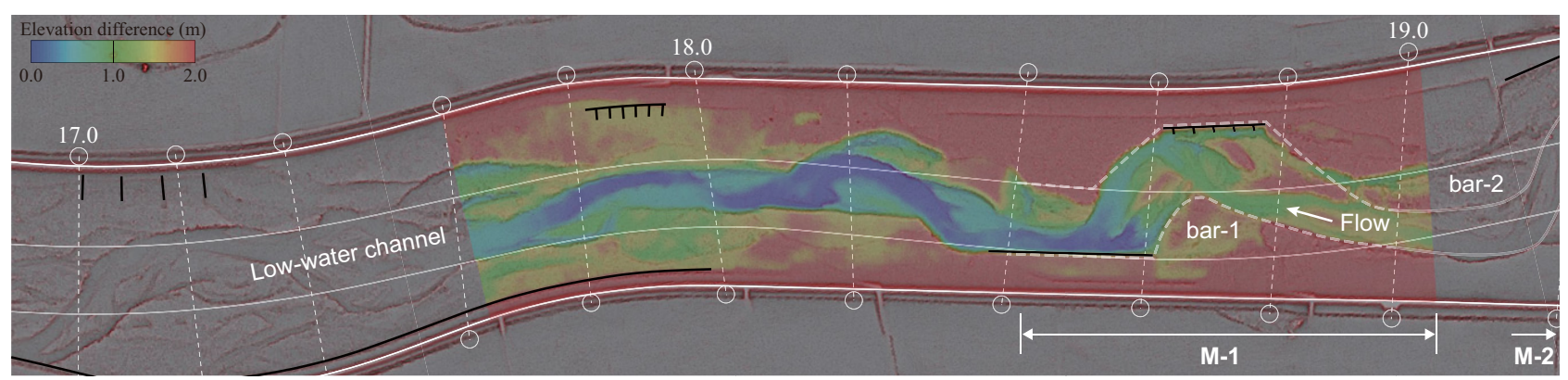

Figure 17. Observed riverbed elevation before the 2011 flood (LP data: 2006.5, Section-2).

an initial riverbed was designed to have a topography imitating the on-site meandering path as described in the previous paragraph. For the rest, the calculation condition used for the analysis of Section-2 was the same as that used for Section-1.

Here, supplementary information is given to show the validity of setting KP19.0 as the upstream end of the analysis section. In the area near KP19.0, due to the point bars (M-1 and M-2), the flow running on the left-bank side was maintained even during a flood, and no transverse direction change in watercourse was observed from that shown in Fig. 19.

In addition, at the site, natural chute cutoffs occurred in the meandering flow (M-2; Figs. 19, 20) during the flood; however, there is no major difference between the cross-sectional shape of the river channel near KP19.0 before the flood and after the flood. In this analysis, therefore, it is assumed that the cross-section profile of KP19.0 (upstream end of calculation range) was in a dynamic equilibrium during the 2011 flood.

\subsection{Calculation results (Section-2) - propagation of meandering waveforms}

The calculation results and the actual configuration of the riverbed measured after the flood are shown in Fig. 21. Additionally, the time display of each result corresponds to those of (1) to (6) and (8) in Fig. 18.

The calculation results confirmed that major changes started to take place in the river channel during the dischargeincrease period after the discharge exceeded $200 \mathrm{~m}^{3} \mathrm{~s}^{-1}$, and the meandering channels took their general form gradually over the period from (2) to (6), around the peak discharge. The changes that took place from (6) to (8) show that only the meandering amplitude was increasing during this period, accompanied by little change in wavelength and phase.

The blue lines show the following change that took place during the period from (2) to (6): the flood flow was restrained in the meander (M-1) due to the curvature of the low-water riverbank, which led to the meandering flow being maintained during the flood. It is considered that, since 


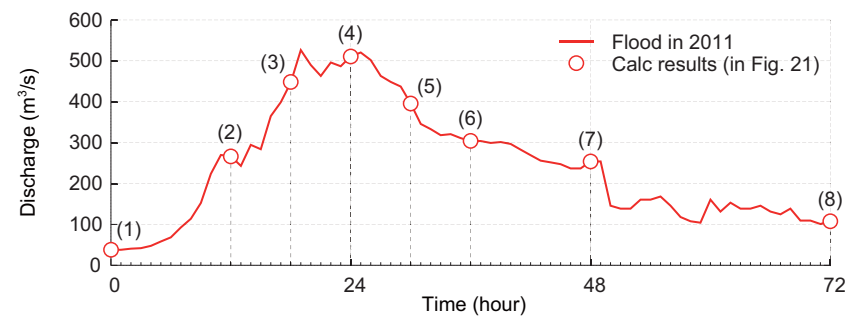

Figure 18. Time display of calculation results (2011 flood).

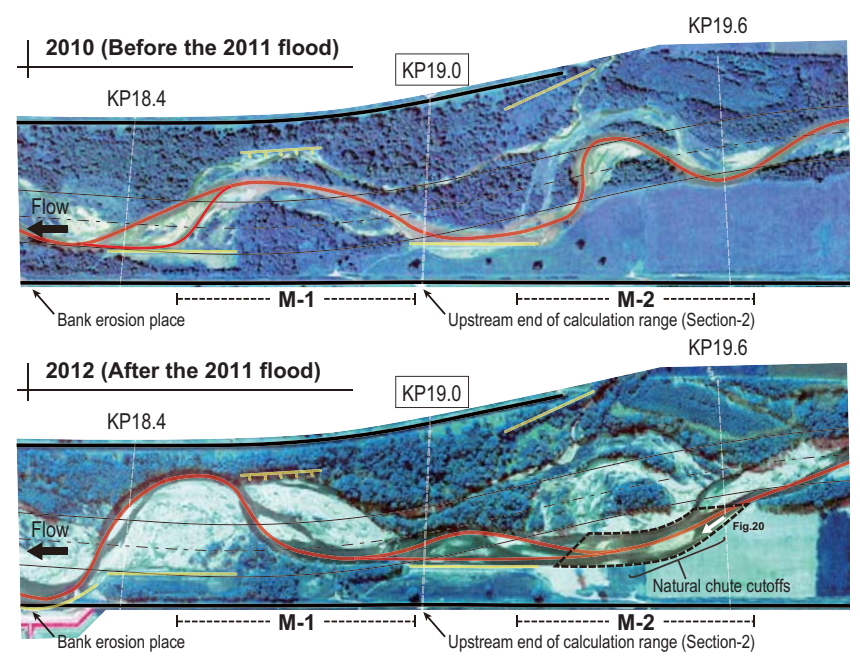

Cross-section profile of KP19.0

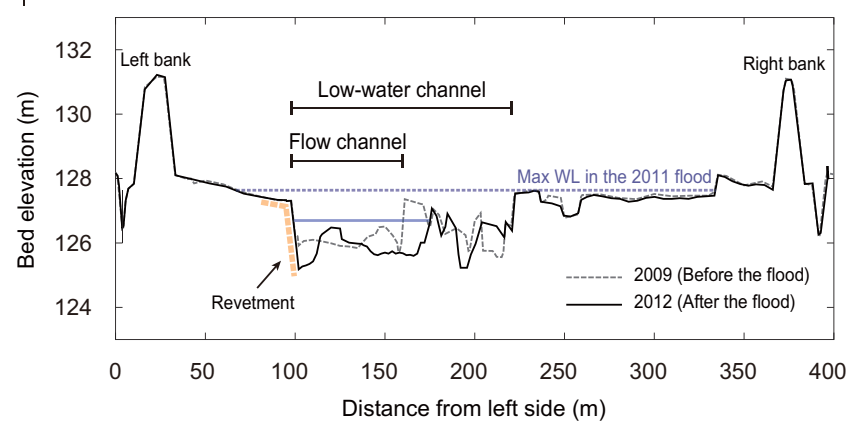

Figure 19. Planform shape of meandering channels and crosssection profiles before and after the 2011 flood (around KP19.0).

this state continued for a long time during the flood, the meandering waveforms of M-1 gradually propagated downstream, which finally led to the formation of uniform meandering channels. Further, at this time, the meandering flow slightly changed its phase to the downstream side while eroding the riverbank. As a result, the location of the riverbank with which the flood flow collided deviated from the existing revetment, which served as a decisive factor in the process leading to this bank disaster.

The contour figure in the bottom of Fig. 21 shows the actual configuration of the riverbed measured after the flood. Comparing it with the calculation results of (8) indicates

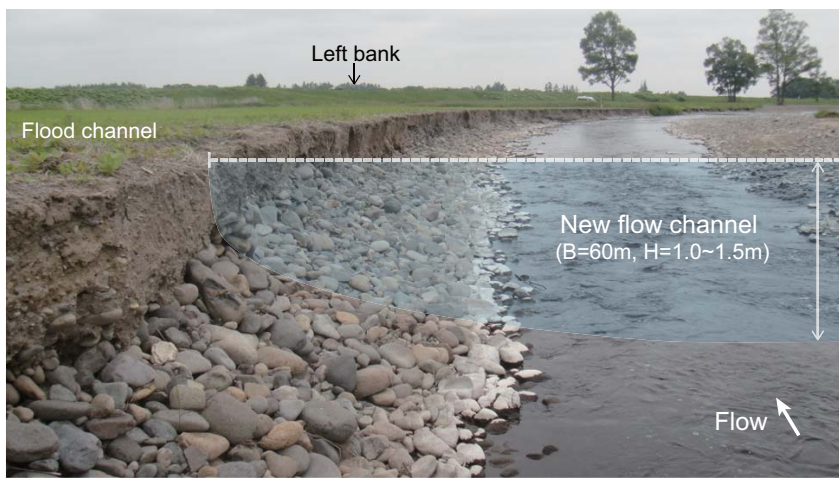

Figure 20. New flow channel caused by the chute cutoffs in M-2.

that the calculation results and the measured data are almost identical in terms of the characteristics of meandering flow (wavelength, amplitude). In particular, there are many similarities between the riverbed configuration of (8) and that of measured data, including phase shifting in $\mathrm{M}-1$, traces of sandbar edge and watercourse left on the formed sandbar, which shows that the obtained calculation results are valid.

Figure 22 shows the sandbar evolution process that was seen in the upstream side of the bank disaster location during the flood. This calculation result indicates that traces of sandbar edge and watercourse formed through the process shown in this figure (Step 1 4). It is considered that meandering flow rapidly shifted towards the river dike due to the bank erosion, as a result, traces of a transverse scrolling sandbar edge is left on the formed sandbar. These characteristics of traces left on the sandbar are very similar to those of the actual place (Fig. 23).

\subsection{Changes of the cross-sectional profile of a sandbar}

In the development of meandering flow, how the crosssectional profile of a sandbar changes with time is extremely important. Here, the cross-sectional profile of an alternating bar is expressed with wave height $H_{B}$ and river width $B$ (Fig. 24), and the time-series variation of a sandbar profile for representative cross sections of Section-1 and Section2 are shown in Fig. 25. The upper part of the figure and Eq. (3) show the following: the results from the experiment on the equilibrium wave height of alternating bars that was conducted using a straight channel and the region where the equilibrium wave height could be found, which was indicated by dimensional analysis (e.g., Ikeda, 1983) and onto which the results obtained from this analysis were overwritten. In addition, the lower part of the figure shows the time-series variation of the cross slopes $\left(H_{B} / B\right)$.

$\frac{H_{B}}{D}=\left(\frac{B}{\mathrm{~d}}\right)^{-0.45} 9.34 \exp \left(2.53 \operatorname{erf} \frac{\log _{10} \frac{B}{D}-1.22}{0.594}\right)$ 


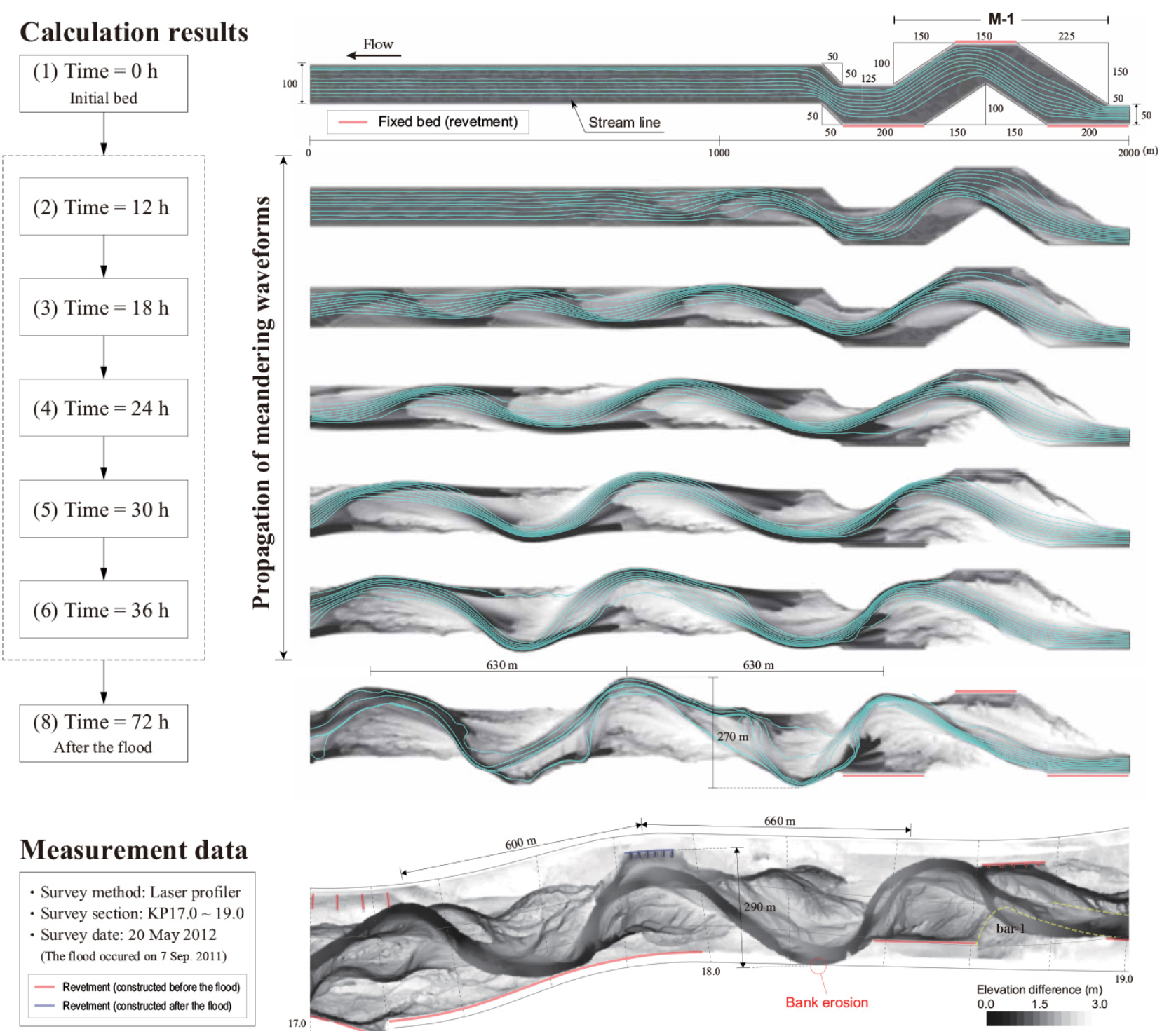

Figure 21. Calculation results and the actual configuration of the riverbed measured after the flood.

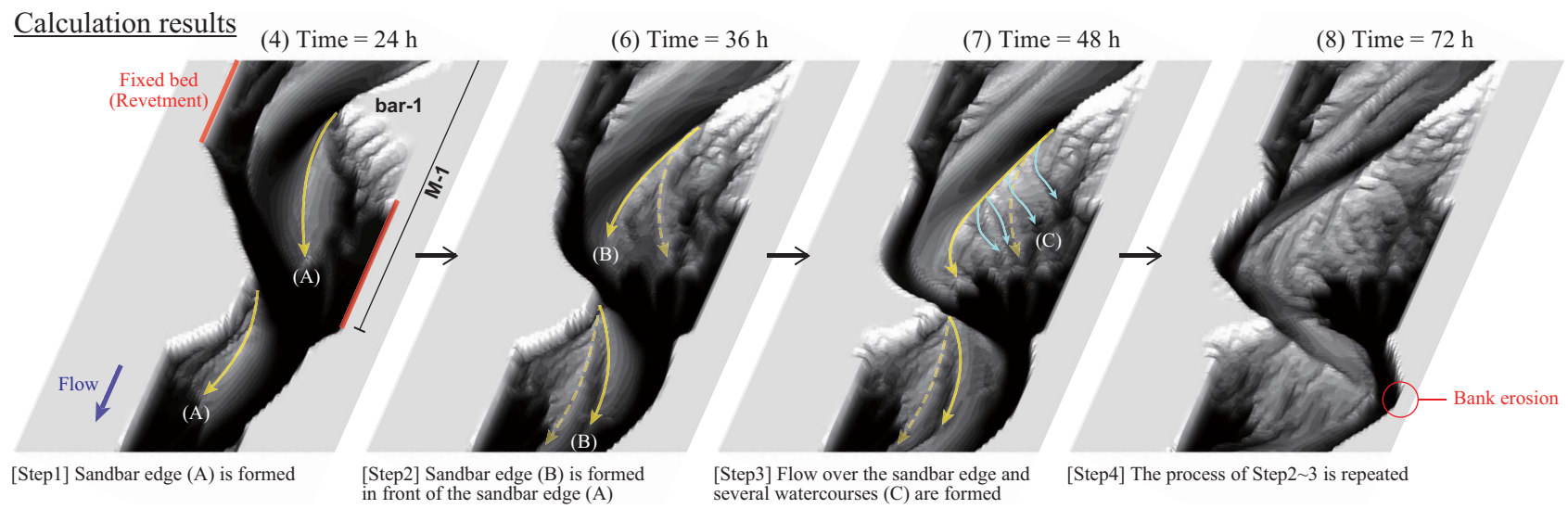

Figure 22. Sandbar evolution process after the peak discharge (traces of sandbar edge and watercourse left on the formed sandbar). 


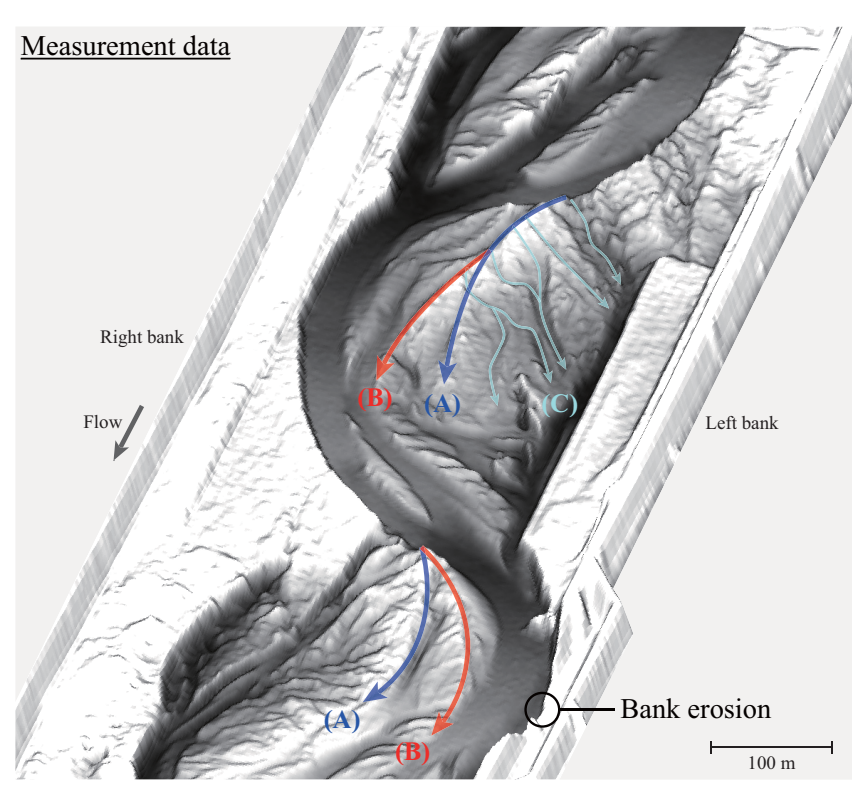

Figure 23. Actual configuration of the riverbed after the 2011 flood.

The details are as follows: $H_{B}$, sandbar wave-height (m); $D$, average water depth (m); $B$, river width (m); and $d$, sand grain size $(\mathrm{m})$.

The two sections can be said to have the following two points in common. The first is that the sandbar wave height increases with time; however, after the sandbar wave height reaches the equilibrium wave height, the sandbar moves while maintaining the same state. The second is that the timeseries variation of the sandbar cross slope reaches the maximum value when the sandbar wave height reaches equilibrium. Thus, both sections show a convex-shaped variation that has the maximum value as its peak value. This result can be roughly interpreted as follows (Fig. 26).

A. Before the wave height has fully developed, the change in the vertical direction predominates (sandbar development process).

B. When the sandbar wave height reaches the equilibrium state, the cross slope also reaches its peak $\left(H_{B} / B=\right.$ $0.020-0.025)$.

C. After that, the change in the transverse direction predominates, while the equilibrium height is maintained (bank erosion process).

In other words, what the sections have in common is that the planform shape of the meandering flow develops after the cross-sectional profile of sandbars has developed. The largest difference between the two sections lies in the time at which the sandbar wave height reaches equilibrium. It is possible to interpret it as follows: in Section-2, where the sandbar wave height reaches equilibrium at an early stage of the flood, bank erosion continues for a prolonged time, which

\section{Cross-section profile}

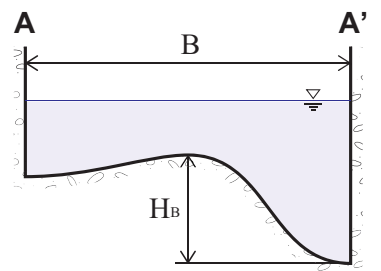

Plane view

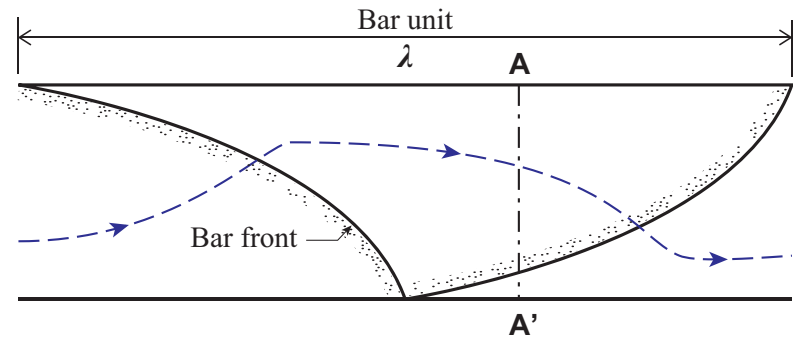

Figure 24. Definition of single-row alternate bars.

leads to the development of meandering flows that is more remarkable than that in Section-1. Additionally, the difference in the timing of when the sandbar wave height reaches the equilibrium wave height is brought about by the presence or absence of the remaining traces in the watercourse or sandbars that were produced during previous floods. Therefore, different planform shapes of river bank were given to Section-1 and Section-2 as the initial riverbeds for analysis. If a highly developed sandbar like M- 1 exists in a low-water channel, it will cause strong meandering flow during a flood. It is assumed that such meandering flow increases the development rate of sandbars to a great degree (peak arrival time of $\left.H_{B} / B\right)$.

\section{Conclusions}

As stated above, this study focused on both sandbar topography and the planform shape of a low-water riverbank, and used numerical analysis to investigate the dominant factors that led to bank damage in September 2011. Based on the analysis of KP18.4-KP21.0, it was presumed that the curvature of the low-water channel had induced the formation of point bars at this section. Also, it was found from the history of the migration of the river course that those sandbars had been gradually increasing the degree of meandering over the course of about 30 years, and their wave height had finally reached the elevation of the low-water riverbank.

Furthermore, on the basis of the results obtained from the analysis on KP17.0 KP19.0, it was presumed that the meandering flows were maintained for a prolonged time due to the planar configuration of the low-water riverbank (curvature) and the meandering waveforms gradually propagated downstream, which finally led to the development of the 

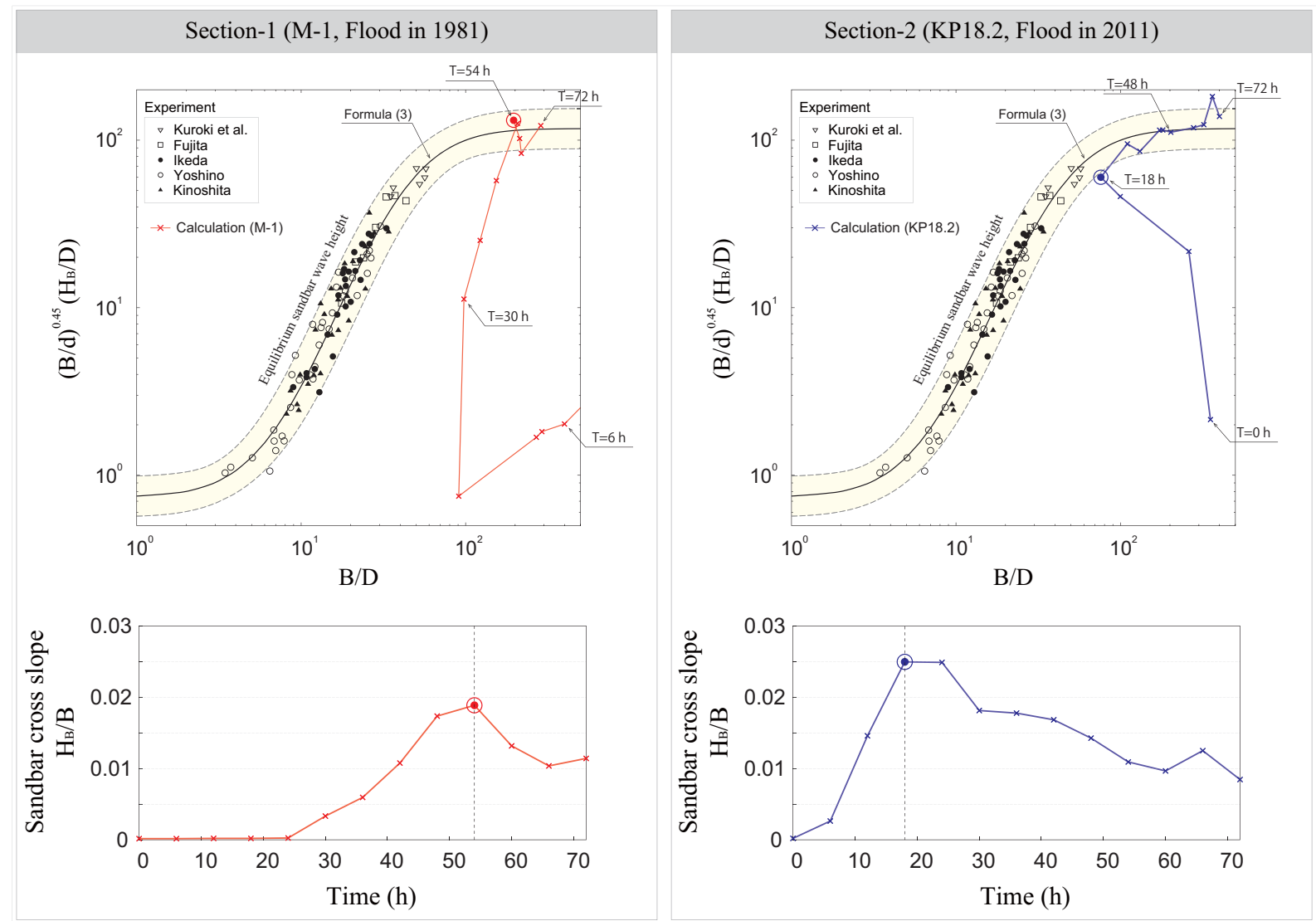

Figure 25. Sandbar wave-height development process and changes of the sandbar cross slope (Sections-1 and 2).

(A) Sandbar development

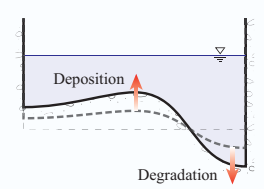

(B) Equilibrium point

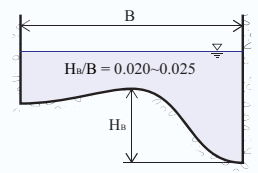

(C) Bank erosion

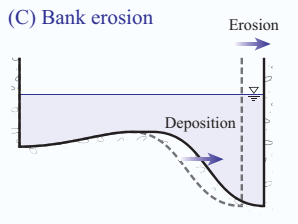

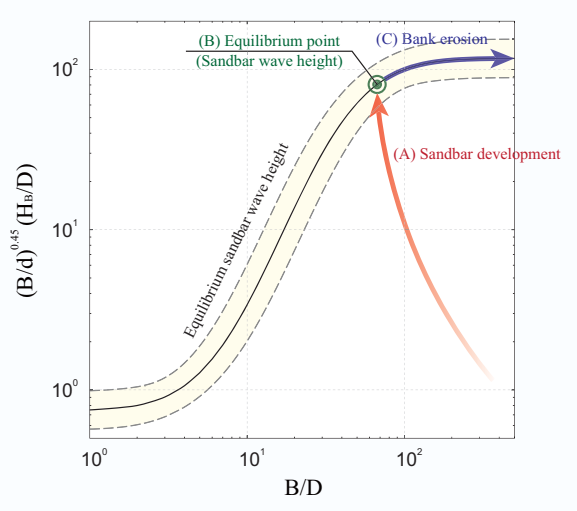

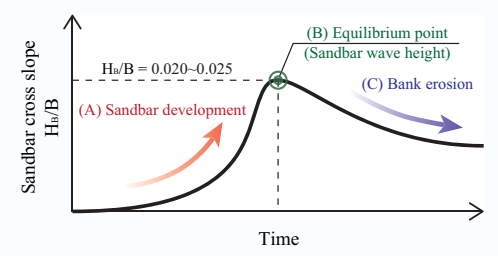

Section-1 (Flood in 1981)

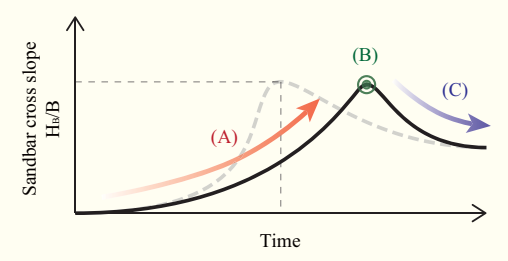

Section-2 (Flood in 2011)

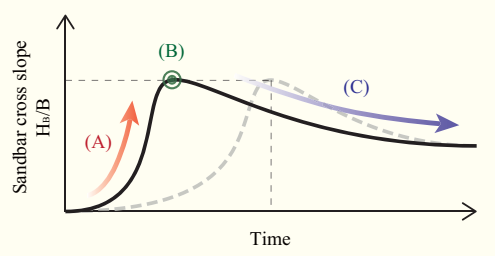

Figure 26. Schematic diagram: change of cross-sectional profile of single-row alternate bars in the flood (Sections-1 and 2). 
large meandering channel that reached the river dike. The following are the major factors that caused the disaster.

1. Immobilization of the sandbars due to the curvature of the low-water channel.

2. The development of point bars, which occurred over a period of several decades.

3. Propagation of meandering waveforms due to the planform shape of the low-water riverbank.

When temporary measures are taken for the section of a lowwater riverbank where protective measures have not been taken, it is considered to be effective to identify critical locations where the above-mentioned factor 2 is found, and to implement measures that lessen the influence from developed point bars. Specifically, the excavation of the upper portion of sandbars is an effective measure; however, relating to this measure, there are some factors to be carefully examined in the future, including the potential influence that it would have on the downstream side.

Acknowledgements. We are deeply grateful to anonymous reviewers whose comments and suggestions were of inestimable value for our study. We would also like to thank the members of the river engineering research team whose meticulous comments were an enormous help to us. Finally, we would like to express our gratitude to Hokkaido Regional Development Bureau who provided us the aerial photographs and many other data used in this study.

Edited by: F. Metivier

\section{References}

Blondeaux, P. and Seminara, G.: A unified bar-bend theory of river meanders, J. Fluid Mech., 157, 449-470, 1985.

Colombini, M., Seminara, G. and Tubino, M.: Finite-amplitude alternate bars, J. Fluid Mech., 181, 213-232, 1987.

Fukuoka, S. and Yamasaka, M.: Theoretical study on meander development caused by bank erosion and deposition, J. Jpn. Soc. Civ. Eng., 327, 73-85, 1981.

Hasegawa, K.: A Study on flows and bed topographies in meandering channels, J. Jpn. Soc. Civ. Eng., 338, 105-114, 1983.

Hasegawa, K. and Yamaoka, I.: The effect of plane and bed forms of channels upon the meander development, J. Jpn. Soc. Civ. Eng., 296, 143-152, 1980.

Ikeda, H.: On the origin of bars in meandering channels, Bull. ERC., Univ. Tsukuba, 1, 17-31, 1977.

Ikeda, H.: Progress of studies on the origin of bars in meandering rivers, Bull. ERC., Univ. Tsukuba, 15, 11-19, 1991.

Ikeda, H. and Ohta, A.: On the formation of stationary bars in a straight flume, Bull. ERC., Univ. Tsukuba, 10, 105-113, 1986.

Ikeda, H., Iseya, F., and Shinzawa, Y.: Cristate bed configuration in a meander bend, Bull. ERC., Univ. Tsukuba, 9, 27-42, 1985.
Ikeda, H., Lisle, T., Pizzuto, J., Iseya, F., Kodama, Y., Maita, H., Iijima, H., Wei, Y., and Suzuki, M.: Channel response to sediment wave propagation in an experimental channel, Bull. ERC., Univ. Tsukuba, 20, 1-9, 1995.

Ikeda, S.: Wavelenght and height of single row alternate bars, Annu. J. Hydraul. Eng. JSCE, 27, 689-695, 1983.

iRIC website: available at: http://i-ric.org/en/ (last access: October 2013), 2013

Jang, C. and Shimizu, Y.: Numerical simulation of relatively wide shallow channels with erodible banks, ASCE J. Hydraul. Eng., 131, 7, 565-575, 2005.

Kinoshita, R. and Miwa, H.: The flow pass shape by which the location of the sand and gravel bar is stabilized, J. Jpn. Soc. Eros. Control Eng., 94, 12-17, 1974.

Kishi, T. and Kuroki, M.: Bed forms and resistance to flow in erodible-bed channels (1) - hydraulic relations for flow over sand waves -, Bull. Fac. Eng., Hokkaido Univ., 67, 1-23, 1972.

Kondo, Y., Shimizu, Y., Kimura, I., and Parker, G.: Numerical computation of free meandering process of rivers considering effect of slump blocks and inner bank deposition, Annu. J. Hydraul. Eng. JSCE, 53, 769-774, 2009.

Kuroki, M. and Kishi, T.: Regime criteria on bars and braids in alluvial straight channels, J. Jpn. Soc. Civ. Eng., 342, 87-96, 1983.

Kuroki, M. and Kishi, T.: Regime criteria on bed forms and flow patterns in alluvial streams, Bull. Fac. Eng., Hokkaido Univ., 118, $1-12,1984$.

Lajeunesse, E., Malverti, L. and Charru, F.: Bed load transport in turbulent flow at the grain scale: Experiments and modeling, J. Geophys. Res-earth., 115, F04001, doi:10.1029/2009JF001628, 2010.

Lanzoni, S. and Seminara, G.: On the nature of meander instability, J. Geophys. Res., 111, F04006, doi:10.1029/2005JF000416, 2006.

Motta, D., Abad, J. D., Langendoen, E. J., and García, M. H.: The effects of floodplain soil heterogeneity on meander planform shape, Water Resour. Res., 48, W09518, doi:10.1029/2011WR011601, 2012.

Nagata, T., Kakinuma, T., and Kuwamura, T.: River course change and meander characteristics of the Otofuke River, Monthly Report of Civil Engineering Research Institute for Cold Region, 706, 2-11, 2012.

Nagata, T., Watanabe, Y., Yasuda, H., and Ito, A.: Development of a meandering channel caused by a shape of the alternate bars, $\mathrm{J}$ Jpn. Soc. Civ. Eng. Ser. B1, 69, 1099-1104, 2013.

Parker, G. and Johannesson, H.: Observations on several recent theories of resonance and overdeepening in meandering channels, Water Res. M., 12, 379-415, 1989.

Parker, G., Shimizu, Y., Wilkerson, G. V., Eke, E. C., Abad, J. D. Lauer, J. W., Paola, C., Dietrich, W. E., and Voller, V. R.: A new framework for modeling the migration of meandering rivers, Earth Surf. Proc. Land., 36, 70-86, 2011.

Seminara, G., Zolezzi, G., Tubino, M., and Zardi, D.: Downstream and upstream influence in river meandering, Part 2. Planimetric development, J. Fluid Mech., 438, 213-230, 2001.

Shimizu, Y.: Mutual effects of bed and bank deformation in channel plane formation, Annu. J. Hydraul. Eng. JSCE, 47, 643-648, 2003. 
Shimizu, Y., Watanabe, Y., and Toyabe, T.: Finite amplitude bed topography in straight and meandering rivers, J. Jpn. Soc. Civ. Eng., 509, 67-78, 1995.

Shimizu, Y., Hirano, M., and Watanabe, Y.: Numerical calculation of bank erosion and free meandering, Annu. J. Hydraul. Eng. JSCE, 40, 921-926, 1996.

Takahashi, G., and Yasuda, H.: Study on conservation condition of central bars, J. Jpn. Soc. Civ. Eng. Ser. B1, 68, 961-966, 2012.

van Dijk, W. M., van de Lageweg, W. I., and Kleinhans, M. G.: Experimental meandering river with chute cutoffs, J. Geophys. Res., 117, F03023, doi:10.1029/2011JF002314, 2012.

van Dijk, W. M., van de Lageweg, W. I., and Kleinhans, M. G.: Formation of a cohesive floodplain in a dynamic experimental meandering river, Earth Surf. Proc. Land., 38, 1550-1565, doi:10.1002/esp.3400, 2013.
Watanabe, Y.: Weakly nonlinear analysis of bar mode reduction process, Annu. J. Hydraul. Eng. JSCE, 50, 967-972, 2006.

Watanabe, Y. and Kuwamura, T.: Experimental study on mode reduction process of double-row bars, Annu. J. Hydraul. Eng. JSCE, 48, 195-200, 2004.

Watanabe, Y. and Kuwamura, T.: Suitability of weakly nonlinear analysis to mode reduction process of double-row bars, Annu. J. Hydraul. Eng. JSCE, 49, 943-948, 2005.

Watanabe, Y., Sato, K., and Oyama, F.: Experimental study on bar formation under unsteady flow conditions, Annu. J. Hydraul. Eng. JSCE, 46, 725-730, 2002.

Wong, M. and Parker, G.: Reanalysis and correction of bed-load relation of Meyer-Peter and Muller using their own database, J. Hydraul. Eng., 132, 1159-1168, 2006. 